\title{
Aberrant Soluble Epoxide Hydrolase and Oxylipin Levels in a Porcine Arteriovenous Graft Stenosis Model
}

\author{
Christi M. Terry $^{a}$ Mary L. Carlson ${ }^{a}$ Yuxia He $^{a}$ Arzu Ulu $^{d}$ \\ Christophe Morisseau $^{d}$ Donald K. Blumenthal ${ }^{\text {b }}$ Bruce D. Hammock ${ }^{d}$ \\ Alfred K. Cheung ${ }^{\text {a, c }}$ \\ ${ }^{a}$ Division of Nephrology and Hypertension and ${ }^{b}$ Department of Pharmacology and Toxicology, University of \\ Utah, and ' Medical Service, Veterans Affairs Salt Lake City Healthcare System, Salt Lake City, Utah, and \\ ${ }^{\mathrm{d}}$ Department of Entomology and Comprehensive Cancer Center, University of California, Davis, Calif., USA
}

\section{Key Words}

Soluble epoxide hydrolase · P450 epoxygenase - Oxylipins . Neointimal hyperplasia $\cdot$ Arteriovenous-graft stenosis

\section{Abstract \\ Synthetic arteriovenous grafts (AVGs) used for hemodialysis frequently fail due to the development of neointimal hyper- plasia $(\mathrm{NH})$ at the vein-graft anastomosis. Inflammation and smooth-muscle cell (SMC) and myofibroblast proliferation and migration likely play an important role in the pathogen- esis of NH. Epoxyeicosatrienoic acids (EETs), the products of the catabolism of arachidonic acid by cytochrome P450 en- zymes, possess anti-inflammatory, antiproliferative, antimi- gratory and vasodilatory properties that should reduce $\mathrm{NH}$. The degradation of vasculoprotective EETs is catalyzed by the enzyme, soluble epoxide hydrolase (sEH). sEH upregulation may thus contribute to $\mathrm{NH}$ development by the enhanced removal of vasculoprotective EETs. In this study, sEH, cyto- chrome P450 and EETs were examined after AVG placement in a porcine model to explore their potential roles in AVG ste- nosis. Increased sEH protein expression, decreased P450 ep-}

oxygenase activity and dysregulation of 5 oxylipin mediators were observed in the graft-venous anastomotic tissues when compared to control veins. Pharmacological inhibitors of $\mathrm{sEH}$ decreased the growth factor-induced migration of SMCs and fibroblasts, although they had no significant effect on the proliferation of these cells. These results provide insights on epoxide biology in vascular disorders and a rationale for the development of novel pharmacotherapeutic strategies to prevent AVG failure due to $\mathrm{NH}$ and stenosis.

(c) 2014 S. Karger AG, Basel

\section{Introduction}

Stenosis with subsequent thrombosis due to underlying neointimal hyperplasia $(\mathrm{NH})$, that forms most often at the vein-graft anastomosis, is the major cause of the failure of synthetic arteriovenous grafts (AVGs) used for chronic hemodialysis $[1,2]$. Typically, AVG patency rates are $40 \%$ after the first year and decrease to $20 \%$ in 3 years [3]. Strategies to prevent NH formation in AVGs are urgently needed.

\section{KARGER}

E-Mail karger@karger.com www.karger.com/jvr
(C) 2014 S. Karger AG, Basel

$1018-1172 / 14 / 0514-0269 \$ 39.50 / 0$
Dr. Alfred K. Cheung

Division of Nephrology and Hypertension, University of Utah

85 North Medical Drive East

Salt Lake City, UT 84112 (USA)

E-Mail alfred.cheung@hsc.utah.edu 
While many factors contribute to $\mathrm{NH}$ development in the AVG, inflammation appears to play a major role because the synthetic graft material is a stimulus to foreignbody inflammatory responses $[4,5]$. In addition, the surgical placement of the AVG (1) initiates injury to the barrier and vasculoprotective functions of the luminal endothelial cell layer, (2) activates platelets to release inflammatory and proproliferative proteins, (3) triggers dedifferentiation of smooth-muscle cells (SMCs) to become proliferative and migratory and (4) upregulates transforming growth factor- $\beta$ expression that promotes the transition of adventitial fibroblasts into proliferative and secretory myofibroblasts that deposit extracellular matrix [4, 6-10]. The shunting of arterial blood directly into the venous circulation also results in highly disturbed blood flow patterns at the vein-graft anastomosis; this likely induces inflammation and cell proliferation [11].

Vasoactive arachidonic acid metabolites include the prostanoids produced by cyclooxygenases, the leukotriene and lipoxins generated by the lipoxygenases and the epoxyeicosatrienoic acids (EETs) produced by cytochrome P450 epoxygenases. Oxidative fatty acid metabolites from polyunsaturated fatty acids, such as linoleic and eicosapentaenoic acid, have been implicated in vascular homeostasis, and cytochrome $\mathrm{P} 450$ enzymes also produce hydroxylated metabolites, such as 20 -hydroxyeicosatetraenoic acid (20-HETE), that possess generally proinflammatory and prohypertensive properties. Such oxylipids may also be involved in AVG dysfunction, but little is known about their roles in this pathology.

EETs, produced by cytochrome $\mathrm{P} 4502 \mathrm{C}$ and 2J epoxygenases [12], perform potent biological activities including the induction of vasodilation, the inhibition of inflammation, angiogenesis and cell adhesion, proliferation and migration and the inhibition of endothelial cell apoptosis [13-16]. In some cells, EETs inhibit the responses induced by many proinflammatory signaling cascades by blocking the activation of I KB kinase, inhibiting the activation and nuclear translocation of the transcriptional regulator nuclear factor $\kappa B$ [14, 17-19]. EETs also can inhibit the activation of the inflammation-responsive c-Jun-N-terminal kinase [20,21]. They attenuate the expression of some cellular adhesion molecules and decrease the aggregation of platelets and polymorphonuclear cells [22-25]. Another beneficial vascular action of EETs is the promotion of endothelial cell proliferation by the activation of p38 mitogen-activated protein kinase and the prosurvival phosphatidyl- inositol 3-kinase/Akt pathways [26, 27]. EETs thus play an essential role in maintaining vascular structure and functions.

The bioavailability of EETs is primarily regulated by soluble epoxide hydrolase ( $\mathrm{sEH}$ ) [28]. This enzyme is widely distributed in mammalian tissues. It is responsible for the catabolism of the regioisomeric 5,6-EET, 8,9-EET, 11,12-EET and 14,15-EET lipid mediators into dihydroxyeicosatrienoic acids (DHETs) which are biologically less active than EETs [29]. The 11,12-isomers and 14,15 -isomers are the more prevalent regioisomers in the vasculature and the 14,15-isomer is the preferred substrate for $\mathrm{sEH}[13,30]$. The $\mathrm{sEH}$ enzyme plays a role in vascular remodeling in injury-induced vascular stenosis. For example, it was found that pharmacological inhibition of sEH or sEH gene knockout decreased neointimal/ medial ratios in a carotid ligation model and in a femoralcuff injury model in hyperlipidemic mice [31, 32]. Pharmacological inhibitors of sEH have been reported to attenuate end organ damage as well as endothelial dysfunction and inflammation in animal models of cardiovascular diseases such as hypertension, ischemia and hypertrophy [33-38]. Recently, inverse correlations between plasma EET/DHET ratios and both plasma monocyte chemotactic protein-1 and cellular adhesion molecule levels were observed in patients with coronary artery disease [39]. Inasmuch as a lower EET/DHET ratio is a reflection of elevated sEH activity, this observation suggests that elevated sEH activity has a part in the pathogenesis of vascular diseases in humans.

Very recently, an inhibitor of sEH was shown to attenuate cytokine release from human monocyte/macrophages [40]. These intriguing and promising data support the further investigation of oxylipids and $\mathrm{sEH}$ in $\mathrm{AVG}$ dysfunction.

We hypothesized that sEH is overexpressed in the juxta-anastomotic region of the AVG with a subsequent reduction in tissue EET levels and their associated vasculoprotective effects. This study, focusing on the vascular tissues around the vein-graft anastomosis of the AVG in a porcine model, determined: (1) the activities of P450 epoxygenase that catalyzes EET production, (2) the expression and activities of sEH that catabolizes EETs, (3) the cell types and location within the vascular wall in which $s E H$ is expressed and (4) the tissue oxylipin profile. This should provide an insight into the potential pathogenic role of epoxy fatty acid dysregulation in $\mathrm{NH}$ development in AVGs and possibly other vascular disorders, and whether there is a rationale for targeting sEH to prevent AVG failure.
Terry/Carlson/He/Ulu/Morisseau/ Blumenthal/Hammock/Cheung 


\section{Materials and Methods}

\section{Animal Model}

All animal experiments were performed in accordance with the Guidelines for the Care and Use of Laboratory Animals (NIH Publication No. 85-23, revised 1996). The protocol was approved by the Institutional Animal Care and Use Committees of the University of Utah and the Veterans Affairs Salt Lake Healthcare System.

A porcine AVG model was used in which $\mathrm{NH}$ develops at the vein-graft anastomosis consistently around 4 weeks after AVG placement $[41,42]$. This location of $\mathrm{NH}$ is similar to that commonly observed in patients [43]. Yorkshire cross-domestic swine, aged 3 months and weighing approximately $30 \mathrm{~kg}$, underwent surgical placement of unilateral AVG according to our previously published procedure [44]. Postoperatively, graft patency was monitored weekly using Doppler ultrasound (SonoSite, Bothell, Wash., USA) and an L38/10-5 MHz transducer (TITAN, SonoSite).

\section{Surgical Procedures}

For the surgical implantation of the AVG, oral aspirin EC (81 mg/day; Phamaceutical Formulations, Edison, N.J., USA) and clopidogrel (225 mg/day; Bristol-Myers Squibb, New York, N.Y., USA) were administered perioperatively. Enrofloxacin $(5 \mathrm{mg} / \mathrm{kg}$; Bayer, Pittsburgh, Pa., USA) was administered intramuscularly on the day of surgery and daily for the next 3 days. The animals underwent tracheal intubation after anesthetization with an intramuscular injection of xylazine $(4 \mathrm{mg} / \mathrm{kg})$, tiletamine/zolazepam (4 mg/kg; Telazol ${ }^{\circledR}$, Fort Dodge Animal Health, Fort Dodge, Ia., USA) and ketamine (4 mg/kg; Hospira Inc., Lake Forrest, Ill., USA). Anesthesia was maintained with inhalation of $1-3 \%$ isoflurane. Intravenous sodium heparin (100 units/kg; Baxter, Deerfield, Ill., USA) was administered intraoperatively. A 7-cm-long, externally spiral-reinforced expanded polytetrafluoroethylene graft (Bard Peripheral Vascular Inc., Tempe, Ariz., USA) with a 6-mm internal diameter was placed between the common carotid artery and the ipsilateral external jugular vein.

\section{Graft and Tissue Explantation and Processing}

Juxta-anastomotic venous tissues were obtained at various time points, i.e. at 1 day, 3 days, 1 week, 3 weeks or 4 weeks, as previously described [44]. For immunohistofluorescence, tissue sections were fixed in formalin. For all other assays, the explanted vessels were flash-frozen in liquid nitrogen. The tissues were used for histology $(n=13)$, immunoblotting $(n=5)$, sEH and P450 epoxygenase activity assays and oxylipin profiling $(n=4)$.

\section{Immunoblotting Analysis of Tissue and Cell Lysates}

Frozen juxta-anastomotic venous segments explanted $1(\mathrm{n}=1)$ or 3 weeks $(n=2)$ after graft placement were lysed in buffer containing Complete Mini protease inhibitor cocktail (Roche Diagnostics, Mannheim, Germany) and protein concentrations determined by the bicinchoninic acid assay (Pierce, Rockford, Ill., USA). Twenty-five micrograms of the vessel lysates were separated on $4-12 \%$ NuPAGE ${ }^{\circledR}$ Bis-Tris polyacrylamide gels and transferred to nitrocellulose membranes (Invitrogen, Carlsbad, Calif., USA). The membranes were incubated in 5\% dry-milk blocking buffer, and then overnight at $4{ }^{\circ} \mathrm{C}$ with a 1:2,500 dilution of polyclonal rabbit anti-porcine-sEH antibody [45] and a 1:10,000 dilution of monoclonal rabbit-anti-human GAPDH (Cell Signaling, Danvers, Mass., USA). Ten micrograms of lysate from porcine or human cultured SMCs or murine liver were subjected to SDS-PAGE on $10 \%$ gels and transferred to nitrocellulose membranes that were incubated with a 1:200 dilution of rabbit anti-human CYP2J2 (Santa Cruz Biotechnology, Santa Cruz, Calif., USA), or a 1:1,000 dilution of rabbit anti-human sEH (Santa Cruz Biotechnology). For the peptide blocking experiment, anti-sEH antibody was preincubated with sEH-specific blocking peptide (Santa Cruz Biotechnology) prior to immunoblotting. The membranes were washed in Tris-buffered saline/Tween solution (TBST) and incubated with a secondary goat anti-rabbit IgG conjugated to horseradish peroxidase (Santa Cruz Biotechnology). Supersignal ${ }^{\circledR}$ West Dura extended duration substrate kit (Thermo Scientific, Rockford, Ill., USA) was used for chemiluminescent antibody detection on autoradiography film. Densitometry of each band of interest (sEH or GAPDH) was quantified using the Kodak molecular imaging software v 4.5.1 (Molecular Imaging Systems, Carestream Health, Inc., Rochester, N.Y., USA).

\section{Immunohistofluorescence Analysis}

Formalin-fixed and paraffin-embedded tissues were deparaffinized and rehydrated using non-xylene Aqua DePar and Hot Rinse ancillary reagents (Biocare Medical, LLC, Concord, Calif., USA). Antigen retrieval was performed using $10 \mathrm{~mm}$ sodium citrate in an EZ-Retriever System (BioGenex Laboratories Inc., San Ramon, Calif., USA). Nonspecific binding was blocked with $2 \%$ goat serum and the tissue was incubated overnight at $4{ }^{\circ} \mathrm{C}$ with a rabbit anti-porcine sEH antibody (1:200) [45] and an antibody directed against a murine monoclonal anti- $\alpha$-smooth muscle actin (a-SMA) conjugated to phycoerythrin (R\&D Systems, Minneapolis, Minn., USA) or a murine monoclonal anti-smooth muscle myosin heavy chain (SMMHC, Chemicon Int. Inc., Temecula, Calif., USA) at dilutions of 1:100 and 1:150, respectively. Following an overnight incubation and serial washes in TBST, the tissue sections were incubated for $1 \mathrm{~h}$ with an anti-rabbit IgG secondary antibody (Alexa Fluor 488 at 1:200 dilution, Invitrogen) for the detection of $\mathrm{sEH}$, and murine biotin-streptavidin 546 (at 1:200 dilution, Invitrogen) for the detection of SMMHC. After further washing with TBST, a nuclear stain (DAPI-Fluoromount-G, Southern Biotech, Birmingham, Ala., USA) was added.

The slides were analyzed using confocal microscopy (BX61, Olympus America Inc., Center Valley, Pa., USA) at $\times 200$ magnification and excitation wavelengths appropriate for the fluorophores used (405, 488 or $543 \mathrm{~nm})$. Photomultipler settings were determined using secondary antibodies alone as negative controls. Ten 1.5- $\mu \mathrm{m}$ slices were generated using the Fluoview FV1000 software (Olympus). The expression of the protein was semiquantified by determining the pixel intensity in $\mathrm{z}$-stacked images imported into Image J (NIH). The number of DAPI-stained nuclei for each Z-stacked image was also determined and used to calculate the amount of sEH expressed per cell. The sEH expression per cell from two replicate histology sections was averaged for the tissue sample from each animal.

\section{P450 Epoxygenase and sEH Activities}

Explanted venous tissues were flash frozen at either $3(n=3)$ or 6 weeks $(n=1)$ after graft placement for metabolomic analysis. For the analysis of P450 epoxygenase activity, samples were thawed and maintained in sodium phosphate buffer with $5 \mathrm{mM}$ EDTA, $1 \mathrm{mM}$ PMSF and $1 \mathrm{mM} \mathrm{DTT}$ at $4^{\circ} \mathrm{C}$ [46]. After homogenization and centrifugation at $10,000 \mathrm{~g}$ for $10 \mathrm{~min}$ at $4^{\circ} \mathrm{C}$, the supernatant 
was subjected to protein assay and activity measurements. For epoxygenase activity assessment, arachidonic acid $(100 \mu \mathrm{M})$ was added to diluted sample extracts and incubated at $37^{\circ} \mathrm{C}$. After $5 \mathrm{~min}$, $5 \mu$ of NADPH-generating-system solution (100 mM glucose6-phosphate, $6 \mathrm{mM} \mathrm{NADP}{ }^{+}, 6 \mathrm{U} / \mathrm{ml}$ glucose-6-phosphate dehydrogenase in $0.1 \mathrm{M}$ phosphate buffer, $\mathrm{pH} 7.4$ ) was added and incubated for $30 \mathrm{~min}$. Ethanol was then added to the reaction with internal EET standards, vortexed and then centrifuged at 2,500 $\mathrm{g}$ at $4^{\circ} \mathrm{C}$ for $4 \mathrm{~min}$. The supernatants were then assayed by LC/MS/MS for the various EET moieties.

For sEH activities, harvested cells were suspended in $1 \mathrm{ml}$ of chilled sodium phosphate buffer $(0.1 \mathrm{M}, \mathrm{pH} 7.4)$ containing $1 \mathrm{mM}$ of EDTA, PMSF and DTT. The cells were disrupted using a Polytron homogenizer $(9,000 \mathrm{rpm}$ for $30 \mathrm{~s})$. The homogenate was used as enzyme extract. Protein concentration was quantified using the bicinchoninic acid assay (Pierce), with Fraction $\mathrm{V}$ bovine serum albumin as the calibrating standard. Epoxide hydrolase activity was measured using racemic $\left[{ }^{3} \mathrm{H}\right]$-trans-1,3-diphenylpropene oxide (tDPPO) as a substrate [47]. Briefly, $1 \mu \mathrm{l}$ of a 5-mM solution of $\left[{ }^{3} \mathrm{H}\right]-\mathrm{tDPPO}$ in dimethylformamide was added to $100 \mu \mathrm{l}$ of enzyme preparation in sodium phosphate buffer $(0.1 \mathrm{M}, \mathrm{pH} 7.4)$ containing $0.1 \mathrm{mg} / \mathrm{ml}$ bovine serum albumin (final concentration: $50 \mu \mathrm{M}$ ). The enzyme was incubated at $30^{\circ} \mathrm{C}$ for $30 \mathrm{~min}$, and the reaction was quenched by the addition of $60 \mu \mathrm{l}$ of methanol and $200 \mu \mathrm{l}$ of isooctane, which extracts the remaining epoxide from the aqueous phase. Extractions with 1-hexanol were performed in parallel to assess the possible presence of glutathione transferase activity which could also transform the substrate. The activity was followed by measuring the quantity of radioactive diol formed in the aqueous phase using a scintillation counter (Tri-Carb 2810 TR, Perkin-Elmer, Shelton, Conn., USA) [47]. Assays were performed in triplicate.

\section{Tissue Oxylipin Analysis}

Fifty milligrams of porcine anastomotic vein tissues from 3 animals, obtained at 3 weeks after graft placement, or the contralateral unoperated vein tissues were weighed and kept at $-20^{\circ} \mathrm{C}$ for $30 \mathrm{~min}$ with $10 \mu \mathrm{l}$ of an antioxidant solution $(0.2 \mathrm{mg} / \mathrm{ml}$ butyl hydroxytoluene and EDTA), $10 \mu \mathrm{l}$ internal standard and $400 \mu \mathrm{l}$ icecold methanol containing $0.1 \%$ acetic acid and $0.1 \%$ butyl hydroxytoluene. The tissues were homogenized using metal beads in a tissue grinder (Glen Mills Inc., Clifton, N.J., USA) at $30 \mathrm{~Hz}$ for $10 \mathrm{~min}$. Resulting homogenates were stored at $-20^{\circ} \mathrm{C}$ overnight and centrifuged at $10,000 \mathrm{~g}$ at $4^{\circ} \mathrm{C}$ for $10 \mathrm{~min}$. The supernatant was collected and the remaining pellets were washed with $100 \mu \mathrm{l}$ of icecold methanol containing $0.1 \%$ acetic acid and $0.1 \%$ butyl hydroxytoluene. All collected supernatants were diluted with $2 \mathrm{ml}$ distilled water and the oxylipins were extracted using solid-phase extraction. Once the samples had been passed through a cartridge (Oasis HLB C18 cartridge, Waters Corp., Milford, Mass., USA), the bound oxylipins were eluted using ethyl acetate and samples were evaporated to dryness with a vacuum centrifuge. The samples were then redissolved with $50 \mu$ of additional standard solution (instrumental standard) in methanol and measured by mass spectrometry [48].

\section{Cell Proliferation and Migration Studies}

The compounds trans-4-[4-(3-adamantan-1-yl-ureido)-cyclohexyloxy]-benzoic acid (tAUCB) and (3-adamantan-1-ylureido)-dodecanoic acid (AUDA) are selective inhibitors of hu- man sEH, with $50 \%$ inhibition of $1.3 \pm 0.1$ and $3.0 \pm 0.5 \mathrm{nM}$, respectively (observed in biochemical assays) $[49,50]$. SMCs and adventitial fibroblasts were isolated from a normal porcine jugular vein using published techniques [51]. The human aortic SMCs and fibroblasts (Cambrex Bio Science, Chicago, Ill., USA) and the porcine venous SMC and fibroblasts (passages 5-8) were seeded into 96-well tissue culture plates at subconfluence and made quiescent by incubation in media with no serum for $48 \mathrm{~h}$. The cells were pretreated with either dimethylsulfoxide alone or an $\mathrm{sEH}$ inhibitor (AUDA or tAUCB) at $0.1-10 \mu \mathrm{M}$ in the absence or presence of EETs (11,12-EET or 14,15-EET, Cayman Chemical, Ann Arbor, Mich., USA) for $1 \mathrm{~h}$. Cell proliferation was stimulated with either PDGF-AB (50 ng/ml; R\&D Systems) or 10\% FBS for $48 \mathrm{~h}$ and assessed with a colorimetric assay following the manufacturer's protocol (CellTiter 96 AQueous One, Promega, Madison, Wisc., USA). The wounding assay was used for assessing cell migration and was performed by seeding the cells to subconfluence onto 4-chamber slides (Lab-TekII, Nunc, Rochester, N.Y., USA). Quiescent cells were then wounded by dragging a pipette tip across the middle of each chamber. The chambers were washed and medium containing PDGF-AB ( $50 \mathrm{ng} / \mathrm{ml})$ was added to each chamber with or without imatinib $(10 \mu \mathrm{M}$; Gleevec, Novartis Pharmaceuticals Corp., East Hanover, N.J., USA) or AUDA $(10 \mu \mathrm{M})$ and incubated for $24 \mathrm{~h}$. The cells were then fixed in methanol and stained with the Diff-Quick ${ }^{\circledR}$ stain set (Dade Behring, Inc., Newark, Del., USA).

For the migration studies, the human aortic SMCs or human adventitial fibroblasts were serum-starved for $24 \mathrm{~h}$ and pretreated with either dimethylsulfoxide or one of the sEH inhibitors, tAUCB or AUDA, at 1 or $5 \mu \mathrm{M}$ for $1 \mathrm{~h}$. After pretreatment, the cells were seeded onto the upper well of a migration chamber insert (InnoCyte $^{\mathrm{TM}}$ 96-well, Calbiochem, La Jolla, Calif., USA) containing a porous $8-\mu \mathrm{m}$ membrane separating the upper and lower chambers. Chemotaxis was stimulated by the addition of PDGF-AB (25 $\mathrm{ng} / \mathrm{ml}$ ) to minimal culture medium in the lower chamber of the 96-well migration plate. Cells were incubated at $37^{\circ} \mathrm{C}$ in a humidified chamber with $5 \% \mathrm{CO}_{2}$ for $15 \mathrm{~h}$ and then processed according to the manufacturer's instructions for cell detachment and Calcein-AM labeling. Fluorescence quantification of the migrated cells was determined by a fluorescent plate reader with excitation and emission wavelengths of 485 and $520 \mathrm{~nm}$, respectively.

\section{Statistical Analysis}

Values of sEH expression by immunohistofluorescence staining of tissues obtained from juxta-anastomotic venous tissue sections were compared to those obtained from the external jugular veins, i.e. the CVs, using the unpaired Student t test. Separate analyses were performed to compare venous anastomotic tissues obtained from the early postoperative period (within 1 week; $n=5$ ) to controls and to compare venous anastomotic tissues obtained later (at 3 and 4 weeks; $\mathrm{n}=4$ ) to the controls. A p value $<0.05$ was considered to be statistically significant.

Analysis of variance (ANOVA) was used to compare the logtransformed tissue levels of 8,9-EETs, 11,12-EETs and 14,15-EETs between the venous anastomotic tissues and the control veins (CVs). The ANOVA model included separate factors for the various EETs and for the comparison between the venous anastomosis and the $\mathrm{CV}$, with the individual animal treated as a blocking factor. This analysis was used to perform a pooled comparison of the log-transformed tissue levels between the venous anastomosis and CV across the 3 substrates (EETs), and to evaluate if these levels differed.
Terry/Carlson/He/Ulu/Morisseau/ Blumenthal/Hammock/Cheung 


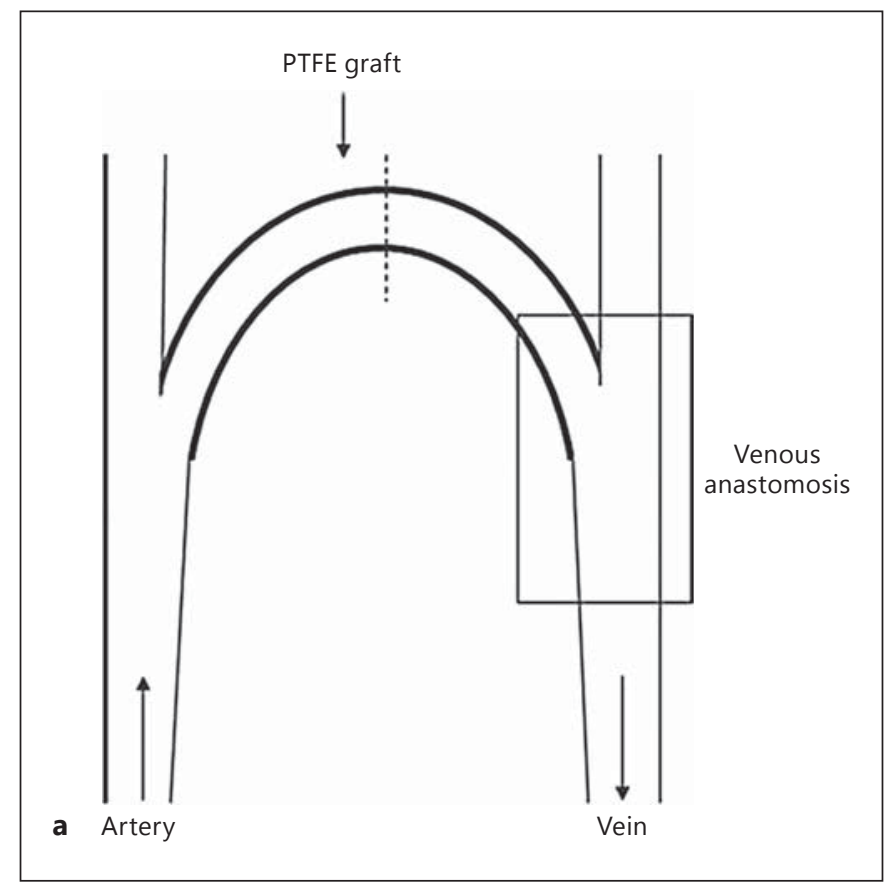

Fig. 1. $\mathrm{sEH}$ expression in tissues of the vein-graft anastomosis after AVG placement in the pig. a Cartoon depicting the polytetrafluoroethylene (PTFE) graft placed between the common carotid artery and ipsilateral external jugular vein. The rectangular box outlines the approximate vein-graft anastomotic area analyzed for sEH and oxylipins in figures 1-5. b Lysates were prepared from the vein-graft anastomotic tissues harvested $1(n=1)$ or 3 weeks $(n=$ 2) after graft placement or from the normal external jugular vein

In exploratory analyses, separate paired $\mathrm{t}$ tests were performed to compare log-transformed tissue levels for 32 oxylipins between venous anastomosis and the $\mathrm{CV}$, with results expressed as the ratio of geometric means with $95 \%$ confidence intervals (CIs). These exploratory analyses were performed on a comparison-wise basis, without adjustment for multiple comparisons. In addition, an unpaired Student $t$ test was used to evaluate differences in fluorescent intensities between cells migrating in the presence or absence of $\mathrm{sEH}$ inhibitors in the migration assay. $\mathrm{p}<0.05$ was considered significant.

\section{Results}

\section{Immunoblotting of sEH in the Tissues of the \\ Vein-Graft Anastomosis}

As stenotic lesions occur most frequently at the veingraft anastomosis, lysates were prepared from the anastomotic venous tissues (fig. 1a) from pigs at 1 or 3 weeks after surgical graft placement. Lysates were also obtained from the external jugular veins from unoperated normal

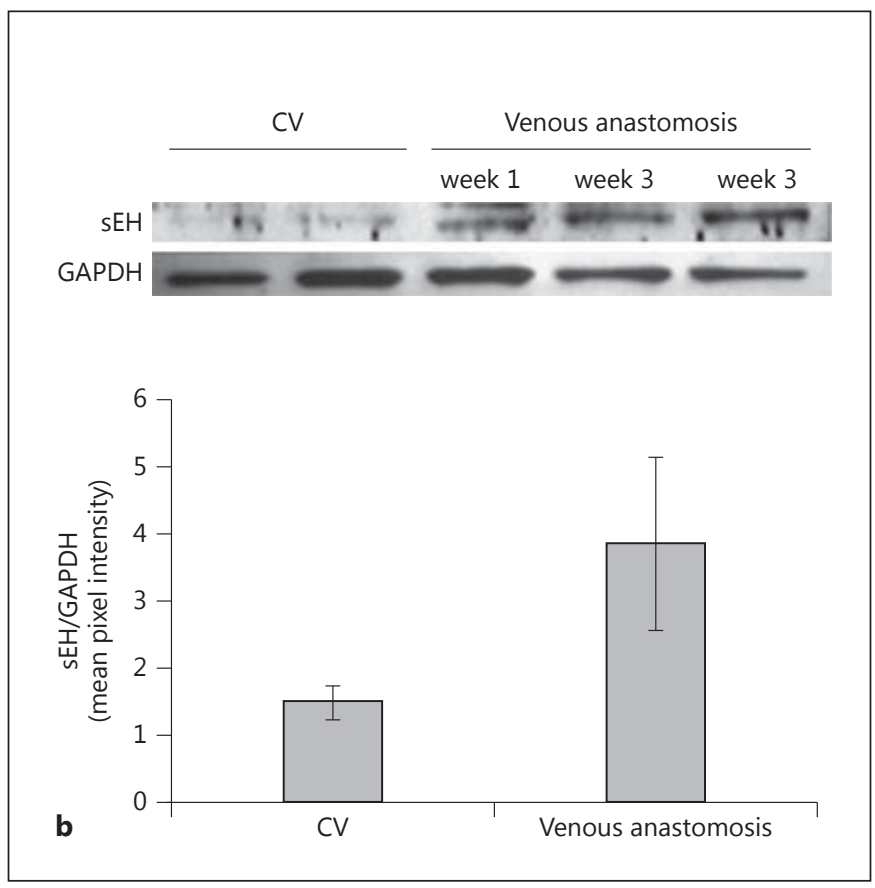

(CV) of an unoperated pig $(\mathrm{n}=2)$, and analyzed by SDS-PAGE followed by immunoblotting with anti-sEH antibody. Protein loading was assessed by immunostaining with anti-GAPDH antibody. Band intensity from sEH immunostaining was measured and protein loading was corrected by dividing by GAPDH band intensity. The normalized sEH band intensity is displayed in a bar graph.

pigs; these served as controls. Levels of sEH protein were determined by immunoblotting. A protein band with an apparent molecular weight of $62 \mathrm{kD}$ was detected with the antiporcine sEH antibody (fig. 1b). Densitometric quantification of these bands showed a 2 -fold increase in $\mathrm{sEH}$ protein in the vein-graft anastomosis tissue compared to the levels observed in the CVs (fig. 1b).

\section{Immunohistofluorescence of sEH in the Tissues of the Vein-Graft Anastomosis}

Immunohistofluorescence was used to confirm the immunoblot finding of elevated sEH expression and to identify the location of the sEH within the vascular wall. The expression of sEH increased in the anastomotic venous tissues early (at 1 week) after graft placement compared to the CVs (fig. 2a). The increased sEH staining was most prominent in the adventitial layer at 1 week, persisting for up to 3 (fig. 2a, b) and 4 weeks (the longest time point examined; data not shown). At 3 weeks, increased $\mathrm{sEH}$ expression was also apparent in the medial layer 
Fig. 2. Expression of $\mathrm{sEH}$ in tissues of the vein-graft anastomosis as determined by immunohistofluorescence and confocal laser scanning microscopy. a Immunohistofluorescence images of a normal external jugular vein (the $\mathrm{CV}$ ) and anastomotic tissues explanted 1 or 3 weeks after AVG placement (sEH staining: green and DAPI nuclear stain: blue). $\times 200$. Scale bars: 50 $\mu \mathrm{m} . \mathrm{A}=$ Adventitia; $\mathrm{L}=$ lumen; $\mathrm{M}=$ media; $\mathrm{N}=$ neovessel. $\mathbf{b}$ Composite semiquantitative data of $s E H$ immunostaining intensity of the CV $(n=4)$ and the vein-graft tissue collected early, i.e. at day $1(\mathrm{n}=1)$, day 3 $(\mathrm{n}=1)$ and after 1 week $(\mathrm{n}=3)$, and then later, i.e. after $3(n=2)$ and 4 weeks $(n=2)$. After normalization against the cell number, sEH expression at the early time points was significantly higher at the venous anastomosis than that observed in the CV $(64.3$ \pm 7.3 vs. $43.8 \pm 16.4$ pixel intensity/cell; $* \mathrm{p}<0.05)$. The $\mathrm{sEH}$ expression remained elevated at the later time points compared to the $\mathrm{CV}(84.7 \pm 13.0$ vs. $43.8 \pm 16.4$ pixel intensity/cell; $\left.{ }^{* *} \mathrm{p}<0.01\right)$.
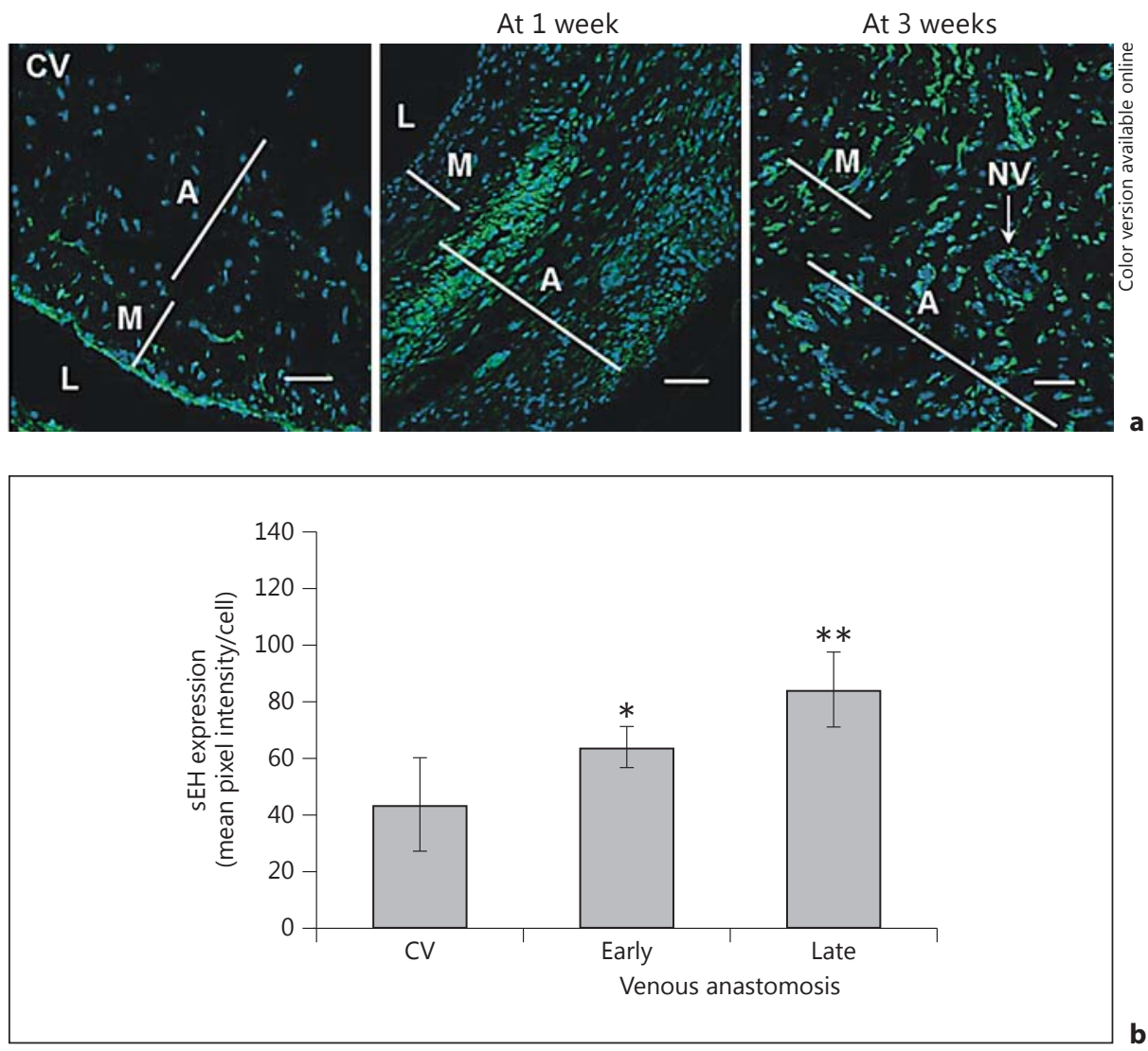

(fig. 2a). Expression of sEH was high in the luminal endothelium of the CV but was decreased in a sporadic fashion in the endothelium at later time points (fig. 2a). The expression of sEH in the entire tissue section was quantified by measuring the pixel intensity of the sEH staining. Even after normalization against the cell number, the increased expression of sEH was apparent within 1 week (early) and remained increased at 3-4 weeks (late) compared to the CVs (fig. 2b).

Immunohistochemical staining with anti-von Willebrand factor antibody revealed some loss of endothelial cells at the anastomotic venous tissues 1 week after AVG placement (data not shown), likely due to surgical trauma. Costaining of sEH and von Willebrand factor was unsuccessful despite repeated attempts. Thus, it could not be determined if the diminished $\mathrm{sEH}$ immunostaining in the luminal cells was as a result of decreased sEH expression or the loss of endothelial cells. Numerous small vessels that stained positive for $\mathrm{sEH}$ were observed in the adventitia at the later time points.
Types of Cells Expressing sEH in the Tissues of the Vein-Graft Anastomosis

Both differentiated quiescent SMCs of normal venous vessels and dedifferentiated synthetic SMCs express a-SMA. Fibroblasts that have dedifferentiated to the migratory and proliferative myofibroblast phenotype acquire the expression of $\alpha$-SMA. In contrast to a-SMA, SMMHC is expressed exclusively by differentiated quiescent SMCs. Thus, an increase in a-SMA expression and a decrease in SMMHC expression suggest the dedifferentiation of quiescent contractile SMCs to the proliferative, synthetic SMC phenotype and/or the presence of myofibroblasts. Such cells are associated with $\mathrm{NH}$ development. Coimmunostaining experiments were performed to examine the colocalization of $s E H$ expression with $\alpha$-SMA and SMMHC expression in the vessel wall. The coexpression of $s E H$ and $\alpha$-SMA in the CVs was limited in nature and was confined to the medial layer (fig. 3a, 1st row). In contrast, in the anastomotic venous tissues collected at 1 week, the coimmunostaining for sEH and $a$-SMA was much stronger, in-
Terry/Carlson/He/Ulu/Morisseau/ Blumenthal/Hammock/Cheung 

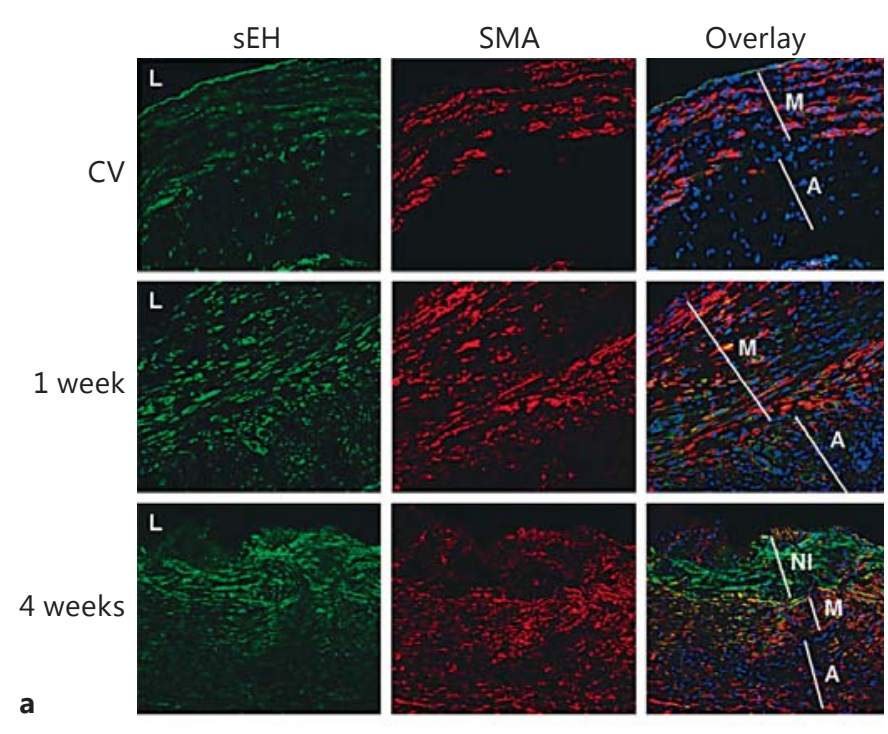
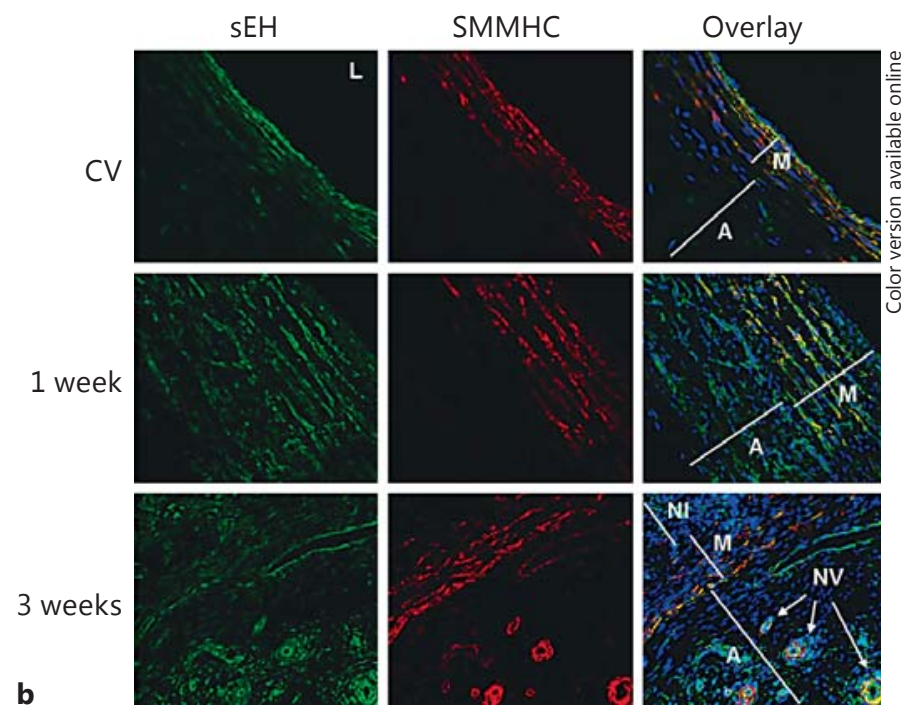

Fig. 3. Characterization of cell types at the vein-graft anastomosis as determined by immunohistofluorescence and confocal laser scanning microscopy. a Sequential histology sections of the anastomotic tissues, obtained at 1 or 3 weeks, and of CVs, were immunostained with anti-sEH (green in left column), anti-a-SMA (red in middle column) or coimmunostained (right column) with anti$s E H$, anti- $\alpha-S M A$ and DAPI nuclear stain (blue). Coexpression of sEH and $\alpha$-SMA appears yellow, or else orange when the $\alpha$-SMA expression was slightly higher than $\mathrm{sEH}$ expression. $\alpha$-SMA expression was confined to the medial layer in the $\mathrm{CV}$, with limited coexpression of sEH and $\alpha$-SMA. In the anastomotic-vein tissue collected at 1 and 4 weeks after graft placement, a-SMA staining was prominent in the adventitia as well as the media. Costaining for sEH and $\alpha$-SMA was conspicuous in the media at 1 week and increased in the media and $\mathrm{NH}$ at 4 weeks (overlay panels). b Sequential histology sections of the anastomotic tissues or CVs were stained with anti-sEH (green in left column) or anti-SMMHC (red in middle column) or coimmunostained (right column) with antisEH, anti-SMMHC and DAPI (blue). In contrast to $\alpha$-SMA, staining for SMMHC was not apparent in the adventitia of AVG tissue, except for at 3 weeks, when SMMHC could be readily observed in or around the neovascular walls (bottom panel of middle column). Costaining of SMMHC with sEH (yellow in the overlay panels) was evident in the media at 1 week, but had mostly disappeared at 3 weeks. In contrast to $\alpha$-SMA, costaining of SMMHC in the $\mathrm{NH}$ region was very low at 3 weeks (overlay panel). A = Adventitia; $\mathrm{L}=$ lumen; $\mathrm{M}=$ media; $\mathrm{NI}=$ neointima; $\mathrm{NV}=$ neovessel.

P450 Epoxygenase and sEH Activities in the Tissues of the Vein-Graft Anastomosis

The levels of 8,9-EET, 11,12-EET and 14,15-EET, the products of tissue $\mathrm{P} 450$ epoxygenase activity, were evaluated in tissue obtained from the vein-graft anastomosis and the CV at 3 weeks. The mean P450 epoxygenase activity to produce all 3 EETs combined was 3.1 and 6.4 $\mathrm{pmol} / \mathrm{min} / \mathrm{mg}$, respectively, in the anastomotic tissues of the 3 animals and the 3 CVs (fig. 4). ANOVA analysis after log-transformation of epoxygenase activity data showed that epoxygenase activities were significantly lower $(\mathrm{p}<0.001)$ in the anastomotic tissues than in the CVs for these EET moieties; the ratio of geometric means of anastomosis to control was 0.54 (95\% CI 0.42-0.71). No difference was observed for the epoxygenase activities generating 5,6-EET (data not shown), an epoxide that is less prevalent and less stable than the 3 aforementioned 


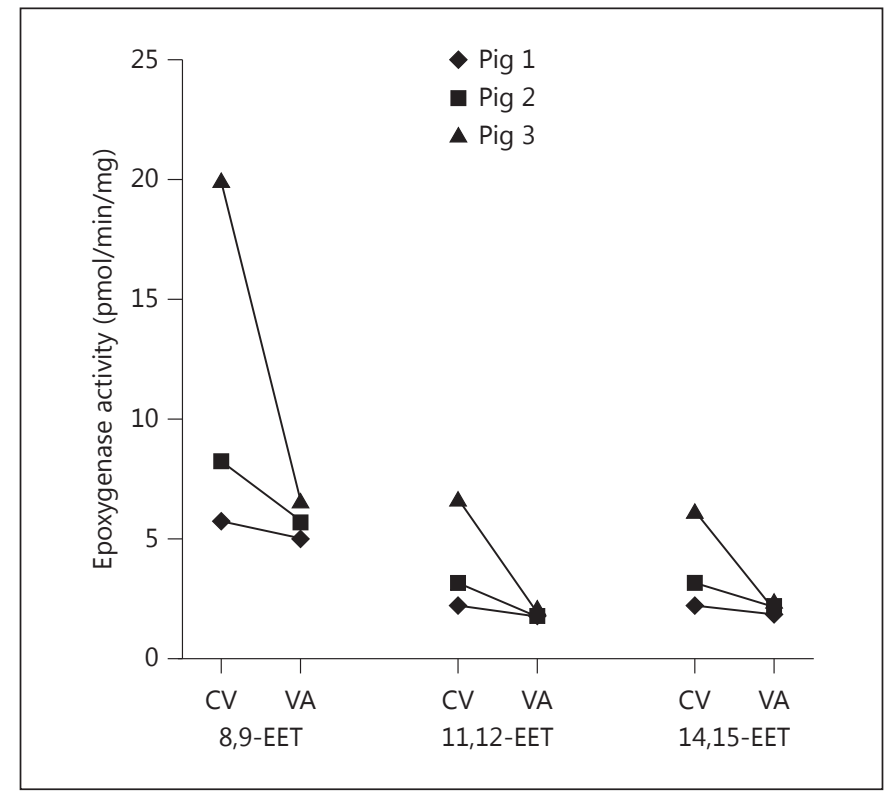

Fig. 4. Epoxygenase and sEH activities in the tissues of the veingraft anastomosis. CYP2C and CYP2J epoxygenase activities were assessed in venous anastomotic (VA) tissues and CVs. The mean levels of 8,9-EET, 11,12-EET and 14,15-EET were lower in the VA tissues than in the CVs $(\mathrm{p}<0.001)$.

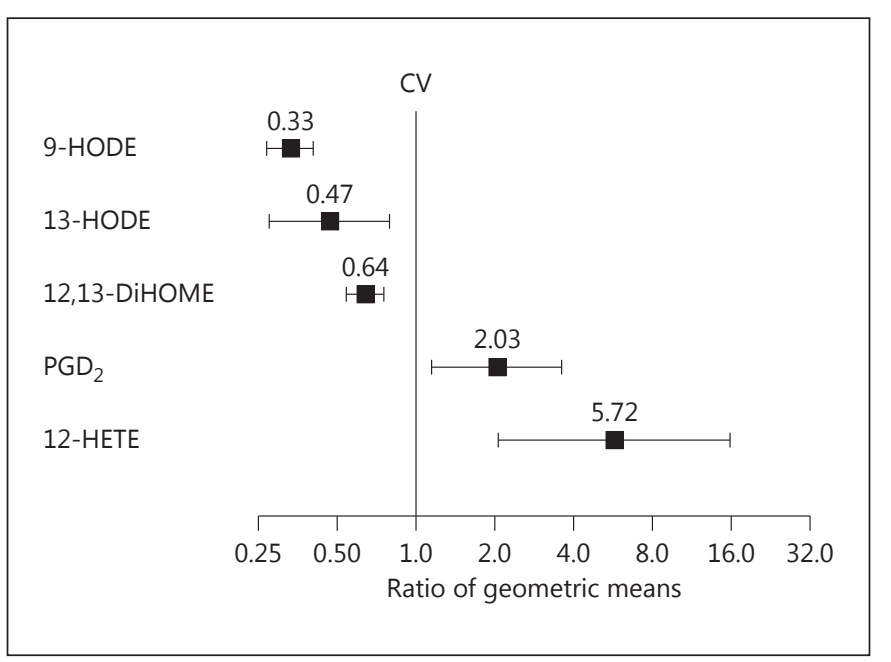

Fig. 5. Five oxylipins with statistically significantly different levels between tissues of the vein-graft anastomosis and CV tissues. The data are displayed as a forest plot of the ratio of geometric means between venous anastomosis $(n=3)$ and CV $(n=3)$ with $95 \%$ CIs. The levels of 9-HODE, 13-HODE and 12,13-DiHOME were decreased, while the levels of $\mathrm{PGD}_{2}$ and 12-HETE were increased in the anastomotic tissues when compared to the CVs $(\mathrm{p}<0.05)$.
Table 1. The ratio of geometric means of oxylipins in the tissue of the vein-graft anastomoses (obtained at 3 weeks after AVG placement) to oxylipins in the CV tissue

\begin{tabular}{|c|c|c|c|}
\hline $\mathrm{N}$ & Oxylipin & $\begin{array}{l}\text { AVG:CV } \\
\text { ratio }\end{array}$ & $95 \% \mathrm{CI}$ \\
\hline 1 & 11-HETE & 0.12 & $0.0-100.6$ \\
\hline 2 & 6-keto-PGF $1 \alpha$ & 0.16 & $0.02-1.45$ \\
\hline 3 & $\mathrm{PGE}_{2}$ & 0.22 & $0.01-4.69$ \\
\hline 4 & Resolvin $\mathrm{E}_{1}$ & 0.37 & $0.07-1.97$ \\
\hline 5 & 15-deoxy-PGJ ${ }_{2}$ & 0.42 & $0.04-4.16$ \\
\hline 6 & 11,12,15-TriHETrE & 0.54 & $0.04-6.74$ \\
\hline 7 & $\mathrm{LTB}_{4}$ & 0.57 & $0.09-3.65$ \\
\hline 8 & 9,10-DiHOME & 0.57 & $0.22-1.5$ \\
\hline 9 & 8,9-DHET & 0.58 & $0.17-1.94$ \\
\hline 10 & 15(S)-HETrE & 0.59 & $0.20-1.73$ \\
\hline 11 & 9-oxo-ODE & 0.68 & $0.08-5.55$ \\
\hline 12 & $\mathrm{LXA}_{4}$ & 0.70 & $0.28-1.74$ \\
\hline 13 & 12,13-EpOME & 0.70 & $0.22-2.27$ \\
\hline 14 & 13-oxo-ODE & 0.76 & $0.01-5.86$ \\
\hline 15 & 9,10-EpOME & 0.79 & $0.16-3.90$ \\
\hline 16 & $\mathrm{TXB}_{2}$ & 0.81 & $0.24-2.68$ \\
\hline 17 & 11,12-DHET & 0.87 & $0.05-15.62$ \\
\hline 18 & 9,10,13-TriHOME & 0.87 & $0.12-6.35$ \\
\hline 19 & 15-HETE & 0.92 & $0.08-10.80$ \\
\hline 20 & 9,12,13-TriHOME & 0.97 & $0.13-7.30$ \\
\hline 21 & 14,15-DHET & 0.97 & $0.27-3.45$ \\
\hline 22 & 5-HETE & 1.12 & $0.63-1.99$ \\
\hline 23 & 11,12-EET & 1.21 & $0.48-3.04$ \\
\hline 24 & 14,15-EET & 1.22 & $0.63-2.39$ \\
\hline 25 & 15-oxo-ETE & 1.33 & $0.11-15.57$ \\
\hline 26 & 8,9-EET & 1.34 & $0.18-9.74$ \\
\hline 27 & 5,6-EET & 1.44 & $0.63-3.31$ \\
\hline 28 & $\mathrm{PGF}_{2 \alpha}$ & 1.59 & $0.35-7.24$ \\
\hline
\end{tabular}

15-deoxy-PGJ $J_{2}=15$-deoxy-prostaglandin $\mathrm{J}_{2} ;$ EpOME $=\mathrm{ep}$ oxyoctadecenoic acid; 6-keto $\mathrm{PGF}_{1 \alpha}=6$-keto-prostaglandin $\mathrm{F}_{1 \alpha}$; $\mathrm{LTB}_{4}=$ leukotriene $\mathrm{B}_{4} ; \mathrm{LXA}_{4}=$ lipoxin $\mathrm{A}_{4} ; 9$-oxo-ODE = oxo-octadecadienoic acid; 15-oxo-ETE $=$ oxo-eicosatetraenoic acid; $\mathrm{PGE}_{2}$ $=$ prostaglandin $\mathrm{E}_{2} ; \mathrm{PGF}_{2 a}=$ prostaglandin $\mathrm{F}_{2 a} ;$ Resolvin $\mathrm{E}_{1}=$ trihydroxyeicosapentaenoic acid; $15(\mathrm{~S})$ - HETrE = hydroxyeicosatrienoic acid; TriHETrE = trihydroxyeicosatrienoic acid; TriHOME $=$ trihydroxyoctadecenoic acid; $\mathrm{TXB}_{2}=$ thromboxane $\mathrm{B}_{2}$.

EETs. sEH activity was also measured in these tissues, but the results were highly variable amongst animals, and there was no significant difference in mean $\mathrm{sEH}$ activity between the venous anastomotic tissues and the CVs $(101.0 \pm 54.9$ and $84.7 \pm 70.2 \mathrm{pmol} / \mathrm{min} / \mathrm{mg})$ at the 3 -week time point. However, venous anastomosis tissue from 1 pig collected 6 weeks after graft placement displayed increased $\mathrm{sEH}$ activity compared to the unoperated femoral vein (77.3 vs. $19.5 \mathrm{pmol} / \mathrm{min} / \mathrm{mg})$. 
Fig. 6. CYP2J2 and sEH expression in SMCs and effect of EETs and/or sEH inhibitor on PDGF-induced proliferation of human SMCs or fibroblasts. a Cell lysates from porcine SMCs were size-fractionated, transferred and then immunostained with anti-sEH antibody in the absence $(-)$ or presence (+) of an sEH-specific blocking peptide (left blot). Lysates from murine liver or human SMCs were immunostained with anti-human CYP2J2 antibody which detected a protein of approximately $57 \mathrm{kD}$ (right blot). b SMCs were serum-starved and then induced to proliferate with PDGF $(50 \mathrm{ng} / \mathrm{ml})$. The addition of EETs $(0.1-10$ $\mu \mathrm{M})$ in the absence or presence of the $\mathrm{sEH}$ inhibitor AUDA $(0.1 \mu \mathrm{M})$ did not inhibit proliferation. c AUDA $(0.1-10 \mu \mathrm{M})$ had no significant effect on fibroblast proliferation induced by $10 \%$ FBS. Each bar represents the mean \pm SD of 3 or 4 observations.
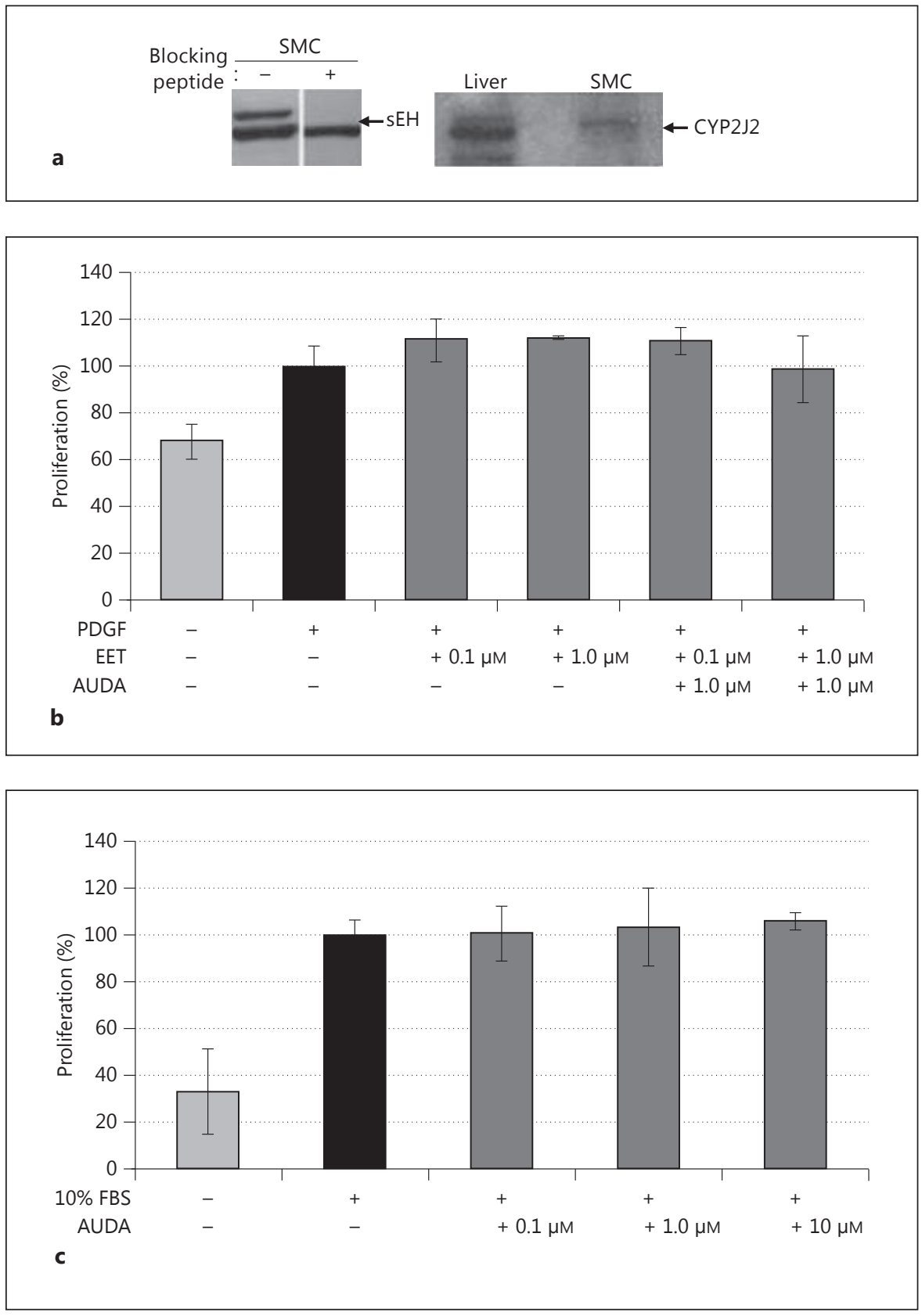

Oxylipin Levels in the Tissues of the Vein-Graft Anastomosis

A profiling of 38 oxylipin levels was performed on the vein-graft anastomotic tissue of 3 animals 3 weeks after AVG placement and was compared to levels in unoperated CVs. Five of the assayed oxylipins were below the limit of detection. The levels of 28 oxylipins in the CVs and the anastomotic tissues were similar (table 1). However, the vein anastomotic tissues displayed significantly decreased levels of 3 oxylipins: 9- and 13-hydroxyoctadecadienoic acid (9-HODE and 13-HODE) and 12,13-dihydroxyoctadecenoic acid (12,13-DiHOME) by 3.0-, 2.1and 1.5 -fold, respectively ( $\mathrm{p}<0.05$, ANOVA; fig. 5). In contrast, prostaglandin $\mathrm{D}_{2}\left(\mathrm{PGD}_{2}\right)$ and 12-HETE were found to be significantly increased by 2.0- and 5.7-fold, respectively, in the anastomotic tissues when compared to the CVs ( $\mathrm{p}<0.05$; fig. 5$)$. 
Fig. 7. Effect of sEH inhibitor (sEHI) AUDA $(10 \mu \mathrm{M})$ and EETs on human SMC migration using a wounding assay. AUDA with or without 11,12 EET inhibited the inward migration of cells into the wounded area in response to PDGF treatment similar to that seen with the PDGF receptor inhibitor, imatinib.
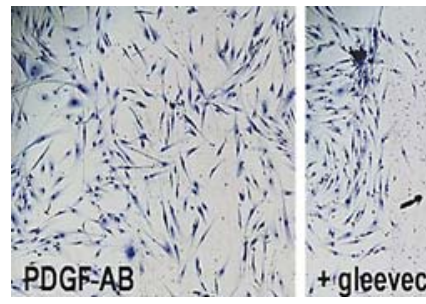
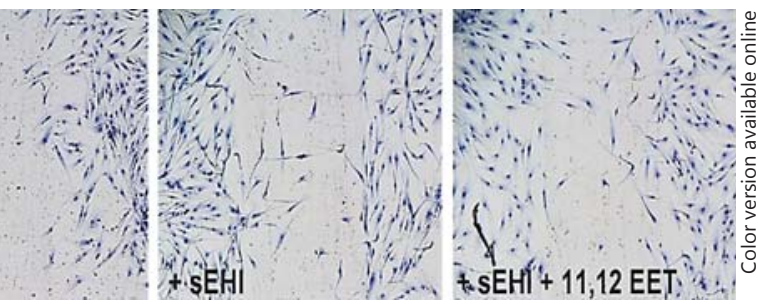
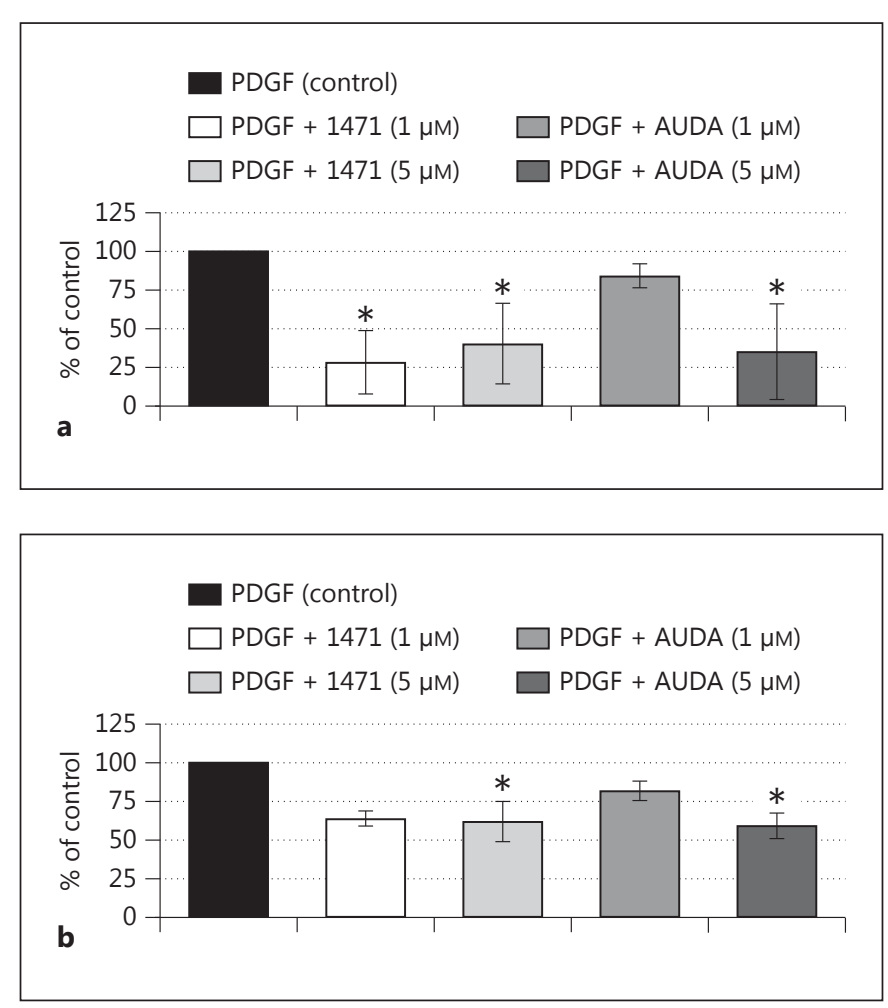

Fig. 8. Effect of sEH inhibitors on PDGF-stimulated migration of human SMCs and fibroblasts through a porous membrane. a Human aortic SMCs were seeded in the upper chamber of the migration apparatus after pretreatment with 1 of 2 concentrations of either AUDA or tAUCB. Migration is shown as a percent of that seen with PDGF alone without inhibitors. b Human adventitial fibroblasts were seeded into the upper chamber after pretreatment with 1 of the 2 inhibitors. ${ }^{*} \mathrm{p}<0.05$ versus PDGF alone.

\section{The Effect of Epoxyeicosatrienoic Acid and sEH}

Inhibitor on Cell Proliferation and Migration

Immunoblotting of lysates from cultured porcine or human SMCs detected sEH protein (fig. 6a, left blot). The P450 epoxygenase isoform CYP2J2 metabolizes arachidonic acid to EETs, and its expression was detected in cultured SMCs (fig. 6a, right blot). However, neither
11,12-EETs nor the combination of EETs and the sEH inhibitor, AUDA, significantly affected the proliferation of SMCs (fig. 6b). Other EETs and different concentrations of AUDA were tested, but also showed no significant effect (data not shown). Figure $6 \mathrm{c}$ shows that AUDA alone had no significant effect on adventitial fibroblast proliferation. Exposure to EETs or AUDA plus EETs did not significantly affect fibroblast proliferation either (data not shown), and exposure to 14,15-EET and/or another pharmacological sEH inhibitor did not attenuate proliferation (data not shown).

The effects of EETs and/or the sEH inhibitor on SMC chemotaxis was determined by both a wounding assay and a Boyden chamber-type assay. Figure 7 shows that AUDA attenuated PDGF-induced human aortic SMC migration across a wound area similar to that observed with imatinib, a PDGF receptor kinase inhibitor. Similarly, two different inhibitors of sEH, i.e. tAUCB and AUDA, attenuated PDGF-induced SMC migration and adventitial fibroblast migration through a porous filter (fig. 8).

\section{Discussion}

Cytochrome P450 epoxygenases metabolize arachidonic acid to EETs which have anti-inflammatory, vasodilatory and other vasculoprotective properties, while sEH rapidly catabolizes the EETs. Other studies have reported the efficacy of sEH inhibitors in attenuating atherosclerosis, abdominal aortic aneurysm formation and hypertension-induced NH in various animal models [3138]. This study addressed the potential role of altered epoxygenase and $\mathrm{sEH}$ pathways in the pathogenesis of $\mathrm{NH}$ associated with AVG in a large animal model.

The expression of sEH was low in the media and adventitia of the unoperated CV but increased early and remained elevated for several weeks in the tissue of the veingraft anastomosis region after AVG placement. Increased $\mathrm{sEH}$ expression was predominant in the medial SMCs 
and cells in the adventitia, concomitant with the appearance of synthetic dedifferentiated SMCs and/or myofibroblasts as determined by the increased expression of a-SMA, a marker of dedifferentiation. Dedifferentiation of SMCs and fibroblasts to a more synthetic phenotype occurs with vascular trauma and results in a greater proliferative and migratory capacity as well as increased synthesis of collagen and other extracellular-matrix proteins [52-54]. We previously reported that adventitial cells become highly proliferative soon after AVG placement in the porcine model, and that these cells, like the medial SMCs, likely contribute to $\mathrm{NH}$ by migrating to the neointima [55]. The early onset of and prolonged increase in sEH protein expression in SMCs and adventitial cells is consistent with the notion that elevated $\mathrm{sEH}$ expression is important in the development of NH in AVGs.

We found that exogenous EETs and/or pharmacological inhibitors of sEH had little effect on the proliferation of SMCs or fibroblasts. In other studies, EETs alone also failed to influence SMC proliferation $[16,56]$. It was previously reported that another $\mathrm{sEH}$ inhibitor attenuated SMC proliferation [57], but the inhibitory effect was later shown to actually be unrelated to the sEH inhibition [58]. $\mathrm{Ng}$ et al. [59] reported that AUDA and EETs inhibited PDGF-BB-induced proliferation of aortic SMCs. These conflicting results across studies could be due to differences in the source of the SMCs (i.e. aortic vs. venous or pulmonary) and/or isoform of the platelet-derived growth factor (PDGF), i.e. PDGF-BB or PDGF-AB, the PDGF concentration employed and/or the timing of the drug exposure.

In our study, neither SMC nor fibroblast proliferation was inhibited, but SMC migration was significantly attenuated by sEH inhibitors; this is similar to the report by Sun et al. [16]. Previous work by our group has also shown that macrophage accumulation and cytokine expression are pronounced features of AVG stenosis and that a pharmacological inhibitor of sEH caused a significant decrease in release of monocyte-chemotactic protein-1 and TNF from lipopolysaccharide-stimulated human monocytes in vitro [40]. The data presented here, together with previous works, suggest that sEH inhibition could be useful for the prevention of AVG stenosis by targeting both inflammation and cell migration.

Decreased activity of the P450 epoxygenases that produce EETs was observed in the vein-graft anastomosis tissue (fig. 4), suggesting a decrease in the production of EETs compared to in the CV tissue. However, no significant difference in 8,9-EET, 11,12-EET or 14,15-EET levels (table 1) was observed in these same lysates, even

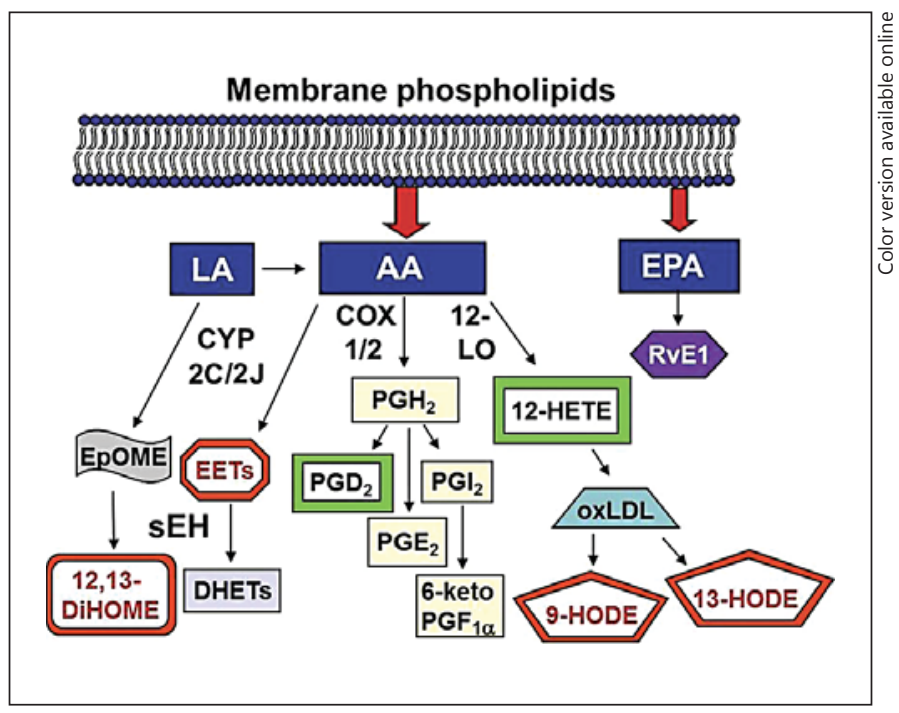

Fig. 9. Proposed cellular arachidonic acid metabolic pathways that contribute to $\mathrm{NH}$ formation at vein-graft anastomosis after AVG placement. Moieties that were observed to be decreased in the venous anastomotic tissues compared to CVs (EETs, 12,13-DiHOME, 9-HODE and 13-HODE) are highlighted by black borders, while moieties that were observed to be increased are highlighted by gray borders. Reduced epoxygenase activity and/or increased sEH activity would contribute to the decreased EET levels and also shunt the polyunsaturated fatty acid substrates to the COX and LO pathways. The proinflammatory mediators $\mathrm{PGD}_{2}$ and 12-HETE were produced by COX1/2 and 12-LO enzymes, respectively. The decreased 9-HODE and 13-HODE levels observed may be the result of decreased oxidation of low-density lipoprotein. $\mathrm{AA}=$ Arachidonic acid; $\mathrm{EPA}=$ eicosapentaenoic acid; COX1/2 = cyclooxygenase 1 or 2 ; CYP2C/2J = cytochrome P450 $2 \mathrm{C}$ or 2J; EpOME = 12,13-epoxyoctadecenoic acid; 6-keto $\mathrm{PGF}_{1 \alpha}=6$-keto-prostaglandin $\mathrm{F}_{1 \alpha} ; \mathrm{LA}=$ linoleic acid; 12-LO = 12-lipoxygenase; $\mathrm{PGE}_{2}=$ prostaglandin $\mathrm{E}_{2} ; \mathrm{PGH}_{2}=$ prostaglandin $\mathrm{H}_{2} ; \mathrm{PGI}_{2}$, = prostacyclin; oxLDL = oxidized low-density lipoprotein; RvE1 = resolvin E1.

though the Western blot and immunohistochemical studies showed an increase in sEH protein levels in the vein-graft tissue. Graft placement triggers drastic changes in blood flow rate and patterns in the vein, and consequently may cause changes in gene expression in the ungrafted contralateral vessels. It is also possible that there were concomitant compensatory decreases in other EET breakdown pathways in the vein-graft tissue. There were significant decreases in 12,13-DiHOME (an isoleukotoxin diol product of the P450 epoxygenase pathway), 9-HODE and 13-HODE (produced during the oxidation of low-density lipoprotein). The 12,13-DiHOME, 9-HODE and 13-HODE are endogenous activating ligands for peroxisome proliferator-activated receptor 
(PPAR) $-\gamma$ [60-62]. The activation of PPAR- $\gamma$ decreases vascular SMC proliferation and migration $[63,64]$ and inhibits the activation of macrophages $[65,66]$. Decreases in these oxylipin PPAR- $\gamma$ agonists after AVG placement may thus contribute to prolonged inflammation and potentiate $\mathrm{NH}$ formation.

Two proinflammatory eicosanoid mediators, $\mathrm{PGD}_{2}$ and 12-HETE, were found to be significantly increased at the vein-graft anastomosis. $\mathrm{PGD}_{2}$ is produced by prostaglandin synthase $\mathrm{D}_{2}$ and has been shown by in vitro studies to be an SMC mitogen released by human umbilical venous endothelial cells following hypoxia [67]. 12-HETE is produced by 12-lipoxygenase activity and has been implicated in angiogenesis, neutrophil aggregation and vasoconstriction [68-72]. Of note, neovessel formation likely supports $\mathrm{NH}$ development by providing nutrients to the growing tissues and allowing access for inflammatory cells. The elevated 12-HETE observed in the veingraft tissue may thus participate in $\mathrm{NH}$ development via promoting neovessel formation.

The various biological activities of the several fatty acid mediators that we found to be dysregulated are consistent with a role for oxylipins in the pathogenesis of $\mathrm{NH}$ in the AVG. Regulation of inflammation and $\mathrm{NH}$ in the AVG appears to be complex, as a result of changes in multiple lipid mediators, cytokines, chemokines and other factors. These proposed lipid metabolic pathways are illustrated in figure 9. Since both the propagation and resolution of inflammation are critical pathophysiological and physiological processes, therapeutic alteration of these processes can have complex outcomes. Nonetheless, targeting sEH and other related key enzymes may be an effective therapeutic strategy to prevent $\mathrm{NH}$ in the AVG.

We acknowledge the following limitations of our study. The porcine model used for this study develops inflammation, $\mathrm{NH}$ and graft stenosis similar to that seen in humans. However, the animals had intact kidney function, and it is possible that impaired kidney function would accelerate such processes and/or alter sEH expression. This work used a costly, labor-intensive, large animal model because AVGs cannot reasonably be placed in small animals. The advantage is that data from this model are likely more translatable to patients because the hemodynamics and foreign-body responses are similar to those in humans. The results of the immunoblotting and IHC experiments are consistent with each other and indicate elevated sEH protein in the vein-graft tissue, and are supported by the elevated sEH activity in 1 animal analyzed at 6 weeks after graft placement. However, there is a risk of false discovery, and caution should be taken in interpreting the oxylipin levels and enzyme activity data due to the small number of animals used in the sEH activity experiments. The antiplatelet drugs clopidogrel and aspirin were administered to all animals before and after graft placement surgery. Aspirin is commonly used in chronic hemodialysis patients. It inhibits the cyclooxygenases in the arachidonic acid pathway and may inhibit the production of EETs by competing for the arachidonate substrate. Clopidogrel has no known effects on arachidonate metabolism.

\section{Acknowledgements}

The authors thank Huan Li and Ilya Zhuplatov for performing surgery on the animals. This study was supported by the Veterans Affairs Merit Review Program (A.K.C.). Partial support was provided by the National Institute of Environmental Health Sciences (B.D.H.). The statistics analysis was performed by the University of Utah Study Design and Biostatistics Center under the guidance of Tom Greene, with funding in part from the Public Health Services research grants (No. UL1-RR025764 and No. C06-RR11234) from the National Center for Research Resources. B.D.H. is a George and Judy Marcus Fellow of the American Asthma Foundation.

\section{References}

1 Feldman HI, Kobrin S, Wasserstein A: Hemodialysis vascular access morbidity. J Am Soc Nephrol 1996;7:523-535.

-2 Gibson KD, et al: Vascular access survival and incidence of revisions: a comparison of prosthetic grafts, simple autogenous fistulas, and venous transposition fistulas from the United States Renal Data System Dialysis Morbidity and Mortality Study. J Vasc Surg 2001;34: 694-700.

3 Dixon BS, et al: Effect of dipyridamole plus aspirin on hemodialysis graft patency. N Engl J Med 2009;360:2191-2201.
4 Ai D, et al: Angiotensin II up-regulates soluble epoxide hydrolase in vascular endothelium in vitro and in vivo. Proc Natl Acad Sci USA 2007;104:9018-9023.

5 Sanders WG, et al: A biodegradable perivascular wrap for controlled, local and directed drug delivery. J Control Release 2012;161:8189.

6 Roy-Chaudhury P, et al: Venous neointimal hyperplasia in polytetrafluoroethylene dialysis grafts. Kidney Int 2001;59:2325-2334.
7 Shi Y, et al: Adventitial myofibroblasts contribute to neointimal formation in injured porcine coronary arteries. Circulation 1996; 94:1655-1664.

8 Tsai S, et al: TGF-beta through Smad3 signaling stimulates vascular smooth muscle cell proliferation and neointimal formation. Am J Physiol Heart Circ Physiol 2009;297:H540H549.

$\checkmark 9$ Roy-Chaudhury P, Sukhatme VP, Cheung AK: Hemodialysis vascular access dysfunction: a cellular and molecular viewpoint. J Am Soc Nephrol 2006;17:1112-1127.
Terry/Carlson/He/Ulu/Morisseau/ Blumenthal/Hammock/Cheung 
10 Weiss MF, Scivittaro V, Anderson JM: Oxida- 25 Pratt PF, Rosolowsky M, Campbell WB: Eftive stress and increased expression of growth factors in lesions of failed hemodialysis access. Am J Kidney Dis 2001;37:970-980.

11 Honda HM, et al: A complex flow pattern of low shear stress and flow reversal promotes monocyte binding to endothelial cells. Atherosclerosis 2001;158:385-390.

$\checkmark 12$ Zeldin DC: Epoxygenase pathways of arachidonic acid metabolism. J Biol Chem 2001;276: 36059-36062.

13 Spector AA, Norris AW: Action of epoxyeicosatrienoic acids on cellular function. Am J Physiol Cell Physiol 2007;292:C996-C1012.

14 Node K, et al: Anti-inflammatory properties of cytochrome P450 epoxygenase-derived eicosanoids. Science 1999;285:1276-1279.

15 Imig JD: Cardiovascular therapeutic aspects of soluble epoxide hydrolase inhibitors. Cardiovasc Drug Rev 2006;24:169-188.

16 Sun J, et al: Inhibition of vascular smooth muscle cell migration by cytochrome p450 epoxygenase-derived eicosanoids. Circ Res 2002;90:1020-1027.

$\checkmark 17$ Kessler P, et al: Proinflammatory mediators chronically downregulate the formation of the endothelium-derived hyperpolarizing factor in arteries via a nitric oxide/cyclic GMP-dependent mechanism. Circulation 1999;99:1878-1884.

18 Node K, et al: Activation of Galpha s mediates induction of tissue-type plasminogen activator gene transcription by epoxyeicosatrienoic acids. J Biol Chem 2001;276:15983-15989.

-19 Spiecker M, Liao JK: Vascular protective effects of cytochrome p450 epoxygenase-derived eicosanoids. Arch Biochem Biophys 2005;433:413-420.

20 Potente M, et al: Cytochrome P450 2C9-induced endothelial cell proliferation involves induction of mitogen-activated protein (MAP) kinase phosphatase-1, inhibition of the c-Jun N-terminal kinase, and up-regulation of cyclin D1. J Biol Chem 2002;277: 15671-15676.

21 Skepner JE, et al: Chronic treatment with epoxyeicosatrienoic acids modulates insulin signaling and prevents insulin resistance in hepatocytes. Prostaglandins Other Lipid Mediat 2011;94:3-8.

22 Falck JR, et al: 11,12-epoxyeicosatrienoic acid (11,12-EET): structural determinants for inhibition of TNF-alpha-induced VCAM-1 expression. Bioorg Med Chem Lett 2003;13: 4011-4014.

$\checkmark 23$ Krotz F, et al: Membrane-potential-dependent inhibition of platelet adhesion to endothelial cells by epoxyeicosatrienoic acids. Arterioscler Thromb Vasc Biol 2004;24:595600.

-24 Heizer ML, McKinney JS, Ellis EF: 14,15-Epoxyeicosatrienoic acid inhibits platelet aggregation in mouse cerebral arterioles. Stroke 1991;22:1389-1393. fects of epoxyeicosatrienoic acids on polymorphonuclear leukocyte function. Life Sci 2002;70:2521-2533.

26 Fleming I, Busse R: Endothelium-derived epoxyeicosatrienoic acids and vascular function. Hypertension 2006;47:629-633.

27 Fleming I, et al: The coronary endotheliumderived hyperpolarizing factor (EDHF) stimulates multiple signalling pathways and proliferation in vascular cells. Pflügers Arch 2001;442:511-518.

28 Newman JW, Morisseau C, Hammock BD: Epoxide hydrolases: their roles and interactions with lipid metabolism. Prog Lipid Res 2005;44:1-51.

29 Daikh BE, et al: Regio- and stereoselective epoxidation of arachidonic acid by human cytochromes P450 2C8 and 2C9. J Pharmacol Exp

$30 \mathrm{Yu} \mathrm{Z}$, et al: Soluble epoxide hydrolase regulates hydrolysis of vasoactive epoxyeicosatrienoic acids. Circ Res 2000;87:992-998.

31 Revermann M, et al: Soluble epoxide hydrolase deficiency attenuates neointima formation in the femoral cuff model of hyperlipidemic mice. Arterioscler Thromb Vasc Biol 2010;30:909-914.

32 Simpkins AN, et al: Soluble epoxide hydrolase inhibition modulates vascular remodeling. Am J Physiol Heart Circ Physiol 2010; 298:H795-H806.

33 Imig JD, Carpenter MA, Shaw S: The soluble epoxide hydrolase inhibitor AR9281 decreases blood pressure, ameliorates renal injury and improves vascular function in hypertension. Pharmaceuticals 2009;2:217-227.

34 Zhao X, et al: Soluble epoxide hydrolase inhibition protects the kidney from hypertensioninduced damage. J Am Soc Nephrol 2004;15: 1244-1253.

35 Koerner IP, et al: Soluble epoxide hydrolase: regulation by estrogen and role in the inflammatory response to cerebral ischemia. Front Biosci 2008;13:2833-2841.

$36 \mathrm{Xu} \mathrm{D}$, et al: Prevention and reversal of cardiac hypertrophy by soluble epoxide hydrolase inhibitors. Proc Natl Acad Sci USA 2006;103: 18733-18738.

37 Zhang LN, et al: Inhibition of soluble epoxide hydrolase attenuated atherosclerosis, abdominal aortic aneurysm formation, and dyslipidemia. Arterioscler Thromb Vasc Biol 2009;29: 1265-1270.

38 Zhang LN, et al: Inhibition of soluble epoxide hydrolase attenuates endothelial dysfunction in animal models of diabetes, obesity and hypertension. Eur J Pharmacol 2011;654:68-74.

39 Schuck RN, et al: Cytochrome P450-derived eicosanoids and vascular dysfunction in coronary artery disease patients. Atherosclerosis 2013;227:442-448.

40 Sanders WG, et al: Soluble epoxide hydrolase expression in a porcine model of arteriovenous graft stenosis and anti-inflammatory effects of a soluble epoxide hydrolase inhibitor. Am J Physiol Cell Physiol 2012;303:C278-C290. Ther 1994;271:1427-1433.
41 Kelly BS, et al: Aggressive venous neointimal hyperplasia in a pig model of arteriovenous graft stenosis. Kidney Int 2002;62:2272-2280.

42 Roy-Chaudhury P, et al: Hemodialysis vascular access dysfunction: from pathophysiology to novel therapies. Blood Purification 2003; 21:99-110.

43 Roy-Chaudhury P, et al: Cellular phenotypes in human stenotic lesions from haemodialysis vascular access. Nephrol Dial Transplant 2009;24:2786-2791.

-44 Kuji T, et al: Efficacy of local dipyridamole therapy in a porcine model of arteriovenous graft stenosis. Kidney Int 2006;69:2179-2185.

45 Newman JW, et al: Cytochrome p450-dependent lipid metabolism in preovulatory follicles. Endocrinology 2004;145:5097-5105.

46 Luria A, et al: Compensatory mechanism for homeostatic blood pressure regulation in Ephx2 gene-disrupted mice. J Biol Chem 2007;282:2891-2898.

47 Borhan B, et al: Improved radiolabeled substrates for soluble epoxide hydrolase. Anal Biochem 1995;231:188-200.

48 Yang J, et al: Quantitative profiling method for oxylipin metabolome by liquid chromatography electrospray ionization tandem mass spectrometry. Anal Chem 2009;81: 8085-8093.

49 Chiamvimonvat N, et al: The soluble epoxide hydrolase as a pharmaceutical target for hypertension. J Cardiovasc Pharmacol 2007;50: 225-237.

50 Morisseau C, et al: Structural refinement of inhibitors of urea-based soluble epoxide hydrolases. Biochem Pharmacol 2002;63:15991608.

51 Li L, et al: PDGF-induced proliferation in human arterial and venous smooth muscle cells: molecular basis for differential effects of PDGF isoforms. J Cell Biochem 2011;112: 289-298.

52 Owens GK, Vernon SM, Madsen CS: Molecular regulation of smooth muscle cell differentiation. J Hypertens Suppl 1996;14:S55-S64.

53 Thyberg J: Phenotypic modulation of smooth muscle cells during formation of neointimal thickenings following vascular injury. Histol Histopathol 1998;13:871-891.

54 Thyberg J, et al: Phenotypic modulation of smooth muscle cells after arterial injury is associated with changes in the distribution of laminin and fibronectin. J Histochem Cytochem 1997;45:837-846.

$55 \mathrm{Li} \mathrm{L}$, et al: Cellular and morphological changes during neointimal hyperplasia development in a porcine arteriovenous graft model. Nephrol Dial Transplant 2007;22:3139-3146.

56 Feng W, et al: EETs and CYP2J2 inhibit TNFalpha-induced apoptosis in pulmonary artery endothelial cells and TGF-beta1-induced migration in pulmonary artery smooth muscle cells. Int J Mol Med 2013;32:685-693.
Aberrant sEH and Oxylipin Levels in AVGs
J Vasc Res 2014;51:269-282 DOI: $10.1159 / 000365251$ 
57 Davis BB, et al: Inhibitors of soluble epoxide hydrolase attenuate vascular smooth muscle cell proliferation. Proc Natl Acad Sci USA 2002;99:2222-2227.

58 Davis BB, et al: Attenuation of vascular smooth muscle cell proliferation by 1-cyclohexyl-3-dodecyl urea is independent of soluble epoxide hydrolase inhibition. J Pharmacol Exp Ther 2006;316:815-821.

$59 \mathrm{Ng}$ VY, et al: Inhibition of smooth muscle proliferation by urea-based alkanoic acids via peroxisome proliferator-activated receptor alpha-dependent repression of cyclin D1. Arterioscler Thromb Vasc Biol 2006;26:24622468.

60 Itoh T, et al: Structural basis for the activation of PPARgamma by oxidized fatty acids. Nat Struct Mol Biol 2008;15:924-931.

-61 Nagy L, et al: Oxidized LDL regulates macrophage gene expression through ligand activation of PPARgamma. Cell 1998;93:229-240.

-62 Ozawa T, et al: Biosynthesis of leukotoxin, 9,10-epoxy-12 octadecenoate, by leukocytes in lung lavages of rat after exposure to hyperoxia. Biochem Biophys Res Commun 1986; 134:1071-1078.
63 Marx N, et al: Peroxisome proliferator-activated receptor gamma activators inhibit gene expression and migration in human vascular smooth muscle cells. Circ Res 1998;83:10971103.

64 Hsueh WA, Jackson S, Law RE: Control of vascular cell proliferation and migration by PPAR-gamma: a new approach to the macrovascular complications of diabetes. Diabetes Care 2001;24:392-397.

65 Ricote M, et al: The peroxisome proliferatoractivated receptor-gamma is a negative regulator of macrophage activation. Nature 1998; 391:79-82.

66 Jiang C, Ting AT, Seed B: PPAR-gamma agonists inhibit production of monocyte inflammatory cytokines. Nature 1998;391:82-86.

67 Michiels C, et al: Hypoxia stimulates human endothelial cells to release smooth muscle cell mitogens: role of prostaglandins and bFGF. Exp Cell Res 1994;213:43-54.
68 Laniado-Schwartzman M, et al: Activation of nuclear factor kappa B and oncogene expression by $12(\mathrm{R})$-hydroxyeicosatrienoic acid, an angiogenic factor in microvessel endothelial cells. J Biol Chem 1994;269:24321-24327.

69 O’Flaherty JT, et al: Neutrophil-aggregating activity of monohydroxyeicosatetraenoic acids. Am J Pathol 1981;104:55-62.

70 Natarajan R, et al: Elevated glucose and angiotensin II increase 12-lipoxygenase activity and expression in porcine aortic smooth muscle cells. Proc Natl Acad Sci USA 1993;90: 4947-4951.

71 Kawasaki K, et al: Inhibition of 12(S)-hydroxyeicosatetraenoic acid (12-HETE) production suppressed the intimal hyperplasia caused by poor-runoff conditions in the rabbit autologous vein grafts. J Cardiovasc Pharmacol 2000;36:555-563.

72 Al-Shabrawey M, et al: Increased expression and activity of 12-lipoxygenase in oxygen-induced ischemic retinopathy and proliferative diabetic retinopathy: implications in retinal neovascularization. Diabetes 2011;60:614624 